\title{
Circular Thinking_A Roundtable on "Blue in Green" and "Nefertiti"
}

\author{
Keith Waters, Henry Martin, Steve Larson, Steven Strunk
}

\section{INTRODUCTION}

Herbie Hancock described one of his mid-1960s jazz compositions by saying "it doesn't have any cadences; it just keeps moving around in a circle." ${ }^{1}$ Many such "circular tunes" emerged in the 1960s, and were particularly associated with Miles Davis. Our joint talk examines two circular jazz compositions. Henry Martin and Steve Larson will discuss "Blue in Green" by Bill Evans, and Keith Waters and Steve Strunk will discuss "Nefertiti" by Wayne Shorter.

Small group jazz improvisation typically features chorus structure. Repeated choruses provide the formal framework for the head and the improvisations. Figure 1 depicts the more common situation. In most standard (that is, noncircular) jazz compositions, harmonic or melodic closure takes place at the end of each chorus. Figure 2, in contrast, shows that circular tunes contain an intriguing formal overlap that both requires and camouflages the return to the top of each chorus. Music events taking place at the end of the chorus avoid closure and link forward to the return at the top of the composition, which no longer sounds like a beginning.

Figure 1. Chorus Structure in Jazz: Non-circular Tunes.



\footnotetext{
${ }^{1}$ Quoted in Baker et al. 1978, 122.
} 
Figure 2. Chorus Structure in Jazz: Circular Tunes.

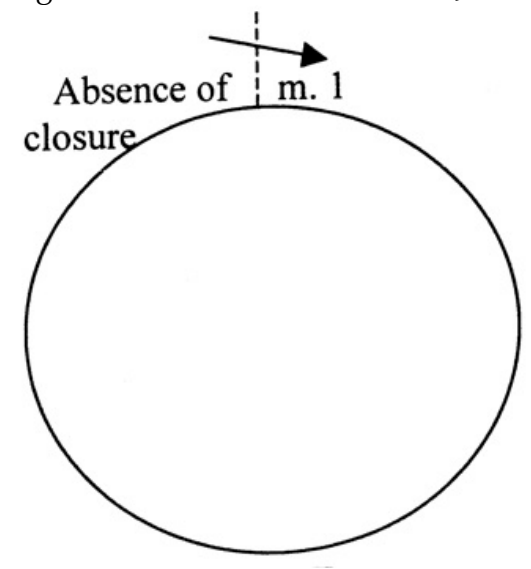

A number of features found in these tunes contribute to their circularity: ${ }^{2}$

- melody: 1) stopping on a note not tonally at rest

2) not stopping, but leading directionally back to the beginning

- harmony: 1) stopping on a non-tonic chord (half cadence on $V$ or other chord)

2) involving the final chord in a structure (e.g., sequence) that leads directionally to the beginning

- form: $\quad$ 1) returning to $A$ in an $A A B$ or $A B$ form, and hence avoiding the more common AABA design

2) having an unusual total number of bars, undermining formal expectations

Our four talks show how circularity arises as a result of one or more of those features. ${ }^{3}$

\footnotetext{
${ }^{2}$ Alexander Stewart offered three general conditions for circularity in a post to the jazz-research listserv on May 24, 2003 (jazz-research@yahoogroups.com). The four co-authors then developed them into this more detailed list.

${ }^{3}$ These talks appear here as delivered at the Society for Music Theory annual meeting on October 29, 2009 at the Hyatt Regency Montréal, with light editing to correct small errors and simplify example references. An earlier version of this roundtable was delivered at the Music Theory Society of the Mid-Atlantic annual meeting on March 28, 2008 at the Library of Congress. While our topic is circularity in jazz tunes, we note that circularity is also operative in the genre of the round, and in works such as Bach's perpetual canon from Ein musikalisches Opfer and Chopin's Mazurka in F minor, op. 68, no. 3 (posthumous), in which the performer is instructed to repeat senza fine. Steve Strunk's comments later in this essay begin with comments on circularity in folk music. Martin and Waters have appended an annotated bibliography and discography to this article with a partial list of circular jazz tunes and other references.
} 
HENRY MARTIN

I will be discussing the tune "Blue In Green," as represented in its lead sheet, and how its harmonic and hypermetrical ambiguities contribute to its circularity. Its lead sheet appears as Example 1. The tune's first appearance was on the album Kind of Blue, recorded March 2, 1959 by the Miles Davis Sextet. ${ }^{4}$ Because Davis interprets the tune freely, I will discuss the published version of the tune, as it appears in the example, rather than Davis's performance.

Example 1 presents the tune on the lower two staves. My analysis, appearing on the upper four staves, shows that the tune can be understood as a composite of two keys, A minor and D minor. Let's begin with some observations on the melody itself.

Example 1. Voice Leading and Intermingling of D Minor and A Minor in "Blue and Green."
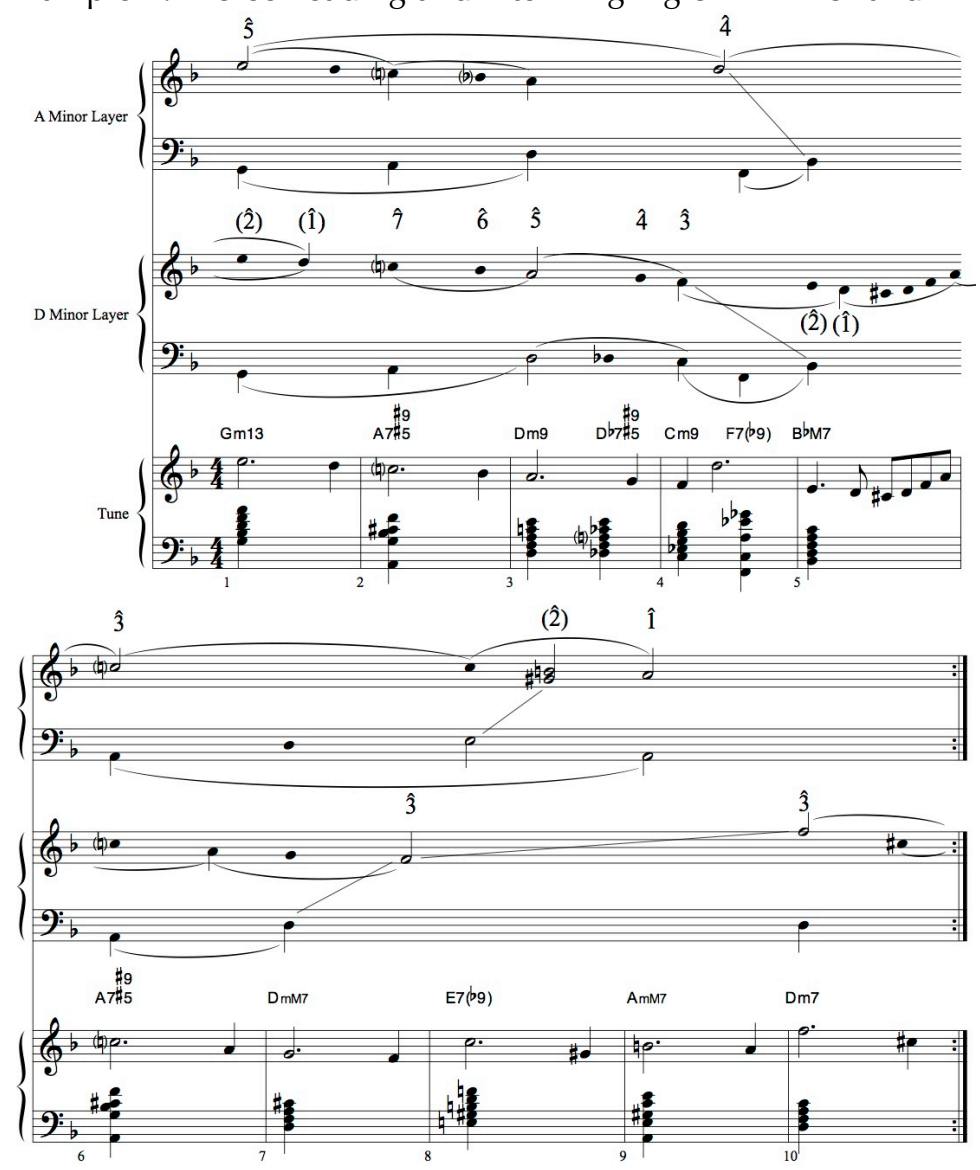

${ }^{4}$ Kind of Blue, Columbia CS1355, 1959; Miles Davis, trumpet; Cannonball Adderley, alto saxophone; John Coltrane, tenor saxophone; Bill Evans, piano; Paul Chambers, bass; Jimmy Cobb, drums. 
Note in particular that the tune is an irregular ten bars long. The downbeats of $\mathrm{mm} .3,5,7$, and 9 are tonicized with standard chord progressions, but perfect authentic cadences, which would project melodic-harmonic closure, are avoided. In mm. 8-9, we find the strongest cadence in the piece, which is to A minor. There, the $\mathrm{G} \#, \mathrm{~B} \boxminus$, and $A$ could be aligned with the $\mathrm{E} 7-\mathrm{Am}$ progression to create a perfect authentic cadence to $\mathrm{A}$ minor, but a melodic delay weakens this moment. Nonetheless, the cadence to A minor in $\mathrm{m} .9$ undermines the harmonic moments that reinforce $\mathrm{D}$ minor, particularly the $\mathrm{A} 7-\mathrm{D}$ progressions in $\mathrm{mm} .2-$ 3 and in $\mathrm{mm} .6-7$.

In Example 1, two voice-leading sketches appear in the four staves above the tune. Please consider the middle staff pair, which shows voice leading within the principal key of $\mathrm{D}$ minor. Here, in $\mathrm{mm} .2-3$, the scalar descent of the beginning can be read as an in-progress structural line. The A4 arrived at in $\mathrm{m} .3$ completes a V7-i cadence in D minor. Indeed, the A4 at $\mathrm{m} .3$ can be read as a Kopfton, with the preceding E-D-C-B $b$ as a kind of descending Anstieg, if you will forgive the contradiction. The line continues to descend to $\hat{3}$ at $\mathrm{m}$. 4 . At $\mathrm{m}$. 5 , completion of the structural line to $\mathrm{E}$ and $\mathrm{D}$ is undermined by the cadence to the $\mathrm{B} b$ major-seventh chord. Rather, the $\hat{3}(\mathrm{~F} 4$ at $\mathrm{m}$. 4) can be heard as prolonged to $\mathrm{F} 4$ in $\mathrm{m}$. 7. This $\mathrm{F} 4$ at $\mathrm{m} .7$ receives tonic support upon resolution of the $\mathrm{G} 4$ on the downbeat. In mm. 8-9, the E7-Am progression can even be thought of as a weak progression to the $\mathrm{D}$ minor in $\mathrm{m}$. 10. That is, if the A minor-major seventh in $\mathrm{m} .9$ were a dominant-seventh chord, then the $\mathrm{F} 4 \mathrm{in} \mathrm{m} .7$ would be prolonged through a transfer of register to $\mathrm{F} 5$ in $\mathrm{m}$. 10. Of course, because the actual chord in $\mathrm{m} .9$ is not a dominant-seventh chord, the prolongation of $\mathrm{F} 4$ at $\mathrm{m} .7$ is weakened; nevertheless, we can still understand it as transferred to F5 at m. 10. This F5 then begins a new descent upon repeat of the tune.

Whether or not we wish to view the A4 in m. 3 as a kind of Kopfton is less significant than the fact that a cadencing structural line in $\mathrm{D}$ minor is lacking. Rather, the dramatic transfer of register between the F4 in $\mathrm{m} .7$ and the F5 in $\mathrm{m}$. 10 and the repeat of the tune assure a continuing lack of $\mathrm{D}$ minor closure.

Against these functions in $\mathrm{D}$ minor, the upper pair of staves in the example shows the simultaneous projection of the key of A minor. From mm. 1-3, the piece begins with a $\hat{5}-\hat{4}-\hat{3}-\hat{2}-\hat{1}$ descent in $\mathrm{A}$ minor, thus outlining an $\mathrm{A}$ minor triad with a Phrygian $\hat{2}$, or $\mathrm{B} b$. In this interpretation, we need to view the E5 in $\mathrm{m} .1$ as a chordal thirteenth prolonged through the unfolding of the A minor triad in $\mathrm{mm} .1-3$. The E5 is then picked up by the D5 in $\mathrm{m}$. 4, which falls outside the descending motions in $\mathrm{D}$ minor discussed previously. The $\mathrm{D} 5 \mathrm{in} \mathrm{m} .4$ is isolated registrally until connection to $\mathrm{C} 5$ at $\mathrm{m}$. 6, where it is supported by an A chord. Then, in m. 8, C5 returns as an appoggiatura that resolves to the 
delayed $\mathrm{B} A$, which properly would be supported by the $\mathrm{E}$ dominant-seventh chord. Hence the Phrygian $\mathrm{B} b$ in m. 2 gives way to the standard second scale degree in $\mathrm{A}$ minor to complete the cadence in $\mathrm{m} .9$ to $\hat{i}$ supported by $\mathrm{A}$ minor. Note also the elegant hidden repetition: the $\hat{5}-\hat{4}-\hat{3}-\hat{2}-\hat{1}$ of $\mathrm{mm}$. $1-3$ extends as a structural line through the entire piece, but with modal shift of $B b$ to $B$.

The interpenetration of the two keys further undermines definitive closure in either of them, as does the tune's 10-bar format, which cuts against typical 4-bar hypermetrical groupings and further enhances its circular nature. A hypermetrical view of the piece appears in Example 2, which shows the keys of A minor and $\mathrm{D}$ minor projecting clashing hypermetrical interpretations. In this example, the tune appears in the lower staff (labeled "c.") of each system. I've rewritten it in double time so that we can more easily compare the 5-hyperbar unit to a hypothetical 4-hyperbar unit.

Example 2. Hypermeter in "Blue and Green."

2a. Hypermeter Extension in A Minor.

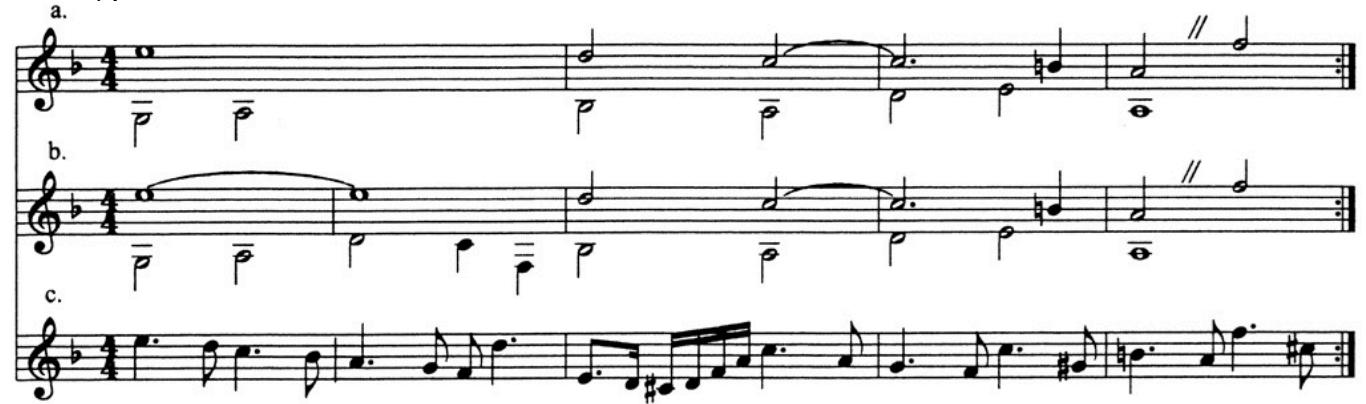

(Tune in double-time)

2b. Hypermeter Extension in D Minor.




The first system in Example 2 shows the tune interpreted in A minor. Staff a. shows a two-voice framework with a normal 4-hyperbar progression in A minor. Staff $b$. shows the phrase extended by a hyperbar at the beginning of the piece. From the 5-hyperbar middle staff, we can then derive the actual tune, shown in the lowest staff. The lower system shows the tune interpreted in D minor. Again, the top line shows a normal 4-hyperbar phrase, which is extended by the addition of a hyperbar in the middle staff. This time, the additional hyperbar falls toward the end of the tune.

Let me summarize my analysis by restating my main point: that Evans artfully balances the keys of A minor and D minor. Most of the chord progressions occur in $\mathrm{D}$ minor. However, $\mathrm{m} .9$ contains the strongest cadence in the piece, which is to A minor. Further, the $\hat{5}-\hat{4}-\hat{3}-\hat{2}-\hat{1}$ structural line in A minor is complete and neatly spans the entire tune. The interpenetration of $\mathrm{A}$ minor and $\mathrm{D}$ minor is further heightened by the ambiguity of the hypermeter. In particular, the 5hyperbar unit can be read in two ways, depending on whether we hear the piece in $\mathrm{A}$ minor or in $\mathrm{D}$ minor.

\section{STEVE LARSON}

I would like to discuss two aspects of "Blue in Green" as it is performed on the recording Kind of Blue. First, I will show how Evans' introduction adds some circular features of its own that set up the tune well, then I will talk briefly about form and hypermeter.

Example 3 offers a transcription and analysis of the introduction, whose harmonic progression is essentially that of the head's $\mathrm{mm}$. 3-10. The lowest two systems give Evans' piano part (labeled "BE") and Paul Chambers' bass part (labeled "PC").

On the middle staff of Example 3b, the whole-note line that begins with F3 (and then jumps a seventh to Eb4 in m. 2) creates parallel tenths with the bass and then resolves to (an implied) D4 at m. 5. This line is shown in Example 3a as the upper voice on its middle staff, a fourth-progression ( $\mathrm{F} 4-\mathrm{C} \# 4$ ) that follows the bass (in the lower staff, D3-A2). The line that begins with an implied D4$\mathrm{C} 4$ in the middle staff of Example $3 \mathrm{~b}$ creates $7-6$ suspensions. ${ }^{5}$ This line is

${ }^{5}$ To further clarify Larson's argument: In the middle staff of Example $3 b$, he uses an unusual over-under symbol to tie the $B \sharp 3$ in $m .1$ to the $B b 3$ in $\mathrm{m}$. 2 . He then views that $B 3$ in $\mathrm{m} .1$ (Example 3b) as generated from a conceptually prior B $b 3$ (shown in the middle staff of Example 3a) that is viewed as tied to a Bb3 in m. 2 (unnotated in Example 3a, but present in Example $3 b$ ) to begin the chain of 7-6 suspensions that he refers to. The Bb3 then resolves to A3 in m. 2 
shown in Example 3a as the lower voice on its middle staff, a sixth progression joining the tonics of mm. 1 and 5. Together these lines work like a Möbius strip; one line begins on $\mathrm{D}$ and moves to $\mathrm{F}$, and the other begins on $\mathrm{F}$ and moves to $\mathrm{D}$.

Example 3. Evans's Introduction to "Blue in Green" on Kind of Blue.

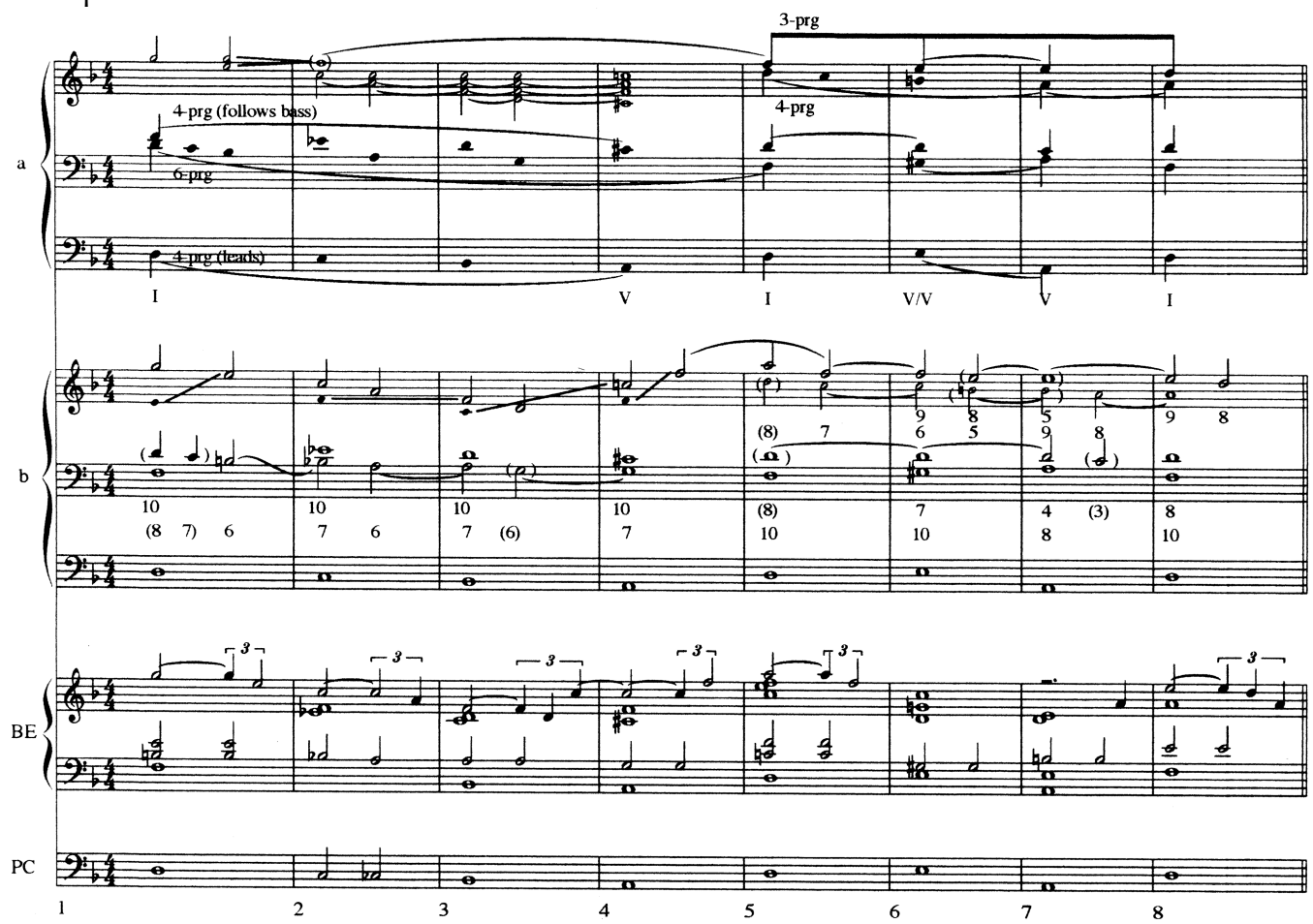

The resultant voice exchange is so seamless in part because of the ways in which Evans uses tone and repetition to mingle these lines in his elegant lefthand voicings. Each follows a simple rule: a third and a seventh/sixth plus a tension (a ninth, eleventh, or thirteenth), usually on top-but the tension (E4) for the $\mathrm{D}$ minor chord moves by half step to both the Eb4 and F4 of the following $\mathrm{C}$ minor voicing, disguising the leap from $\mathrm{F} 3$ to $\mathrm{E} b 4$. All voices of the $\mathrm{D}$ minor voicing are repeated-but only the line that creates the 7-6 suspensions in the following voices is repeated. The result is the feeling of a smooth descent despite the initial leap of a seventh by the line that creates the parallel tenths with the bass.

(middle staff of both Examples 3a and 3b). NB: Here and throughout the article, italics will denote editorial comments. 
In mm. 5-8, the left-hand voicings do not follow the same rule-in fact, the A chord has neither a third nor a seventh/sixth. These last four measures of the introduction are clearly analogous to the last four measures of the head-in fact, the melody $\mathrm{C}-\mathrm{G} \#-\mathrm{B}$ may be found in the repeated notes of the left hand and then taken over by the right hand with its $\mathrm{A}-\mathrm{E}-\mathrm{D}-\mathrm{A}(\mathrm{mm} .7-8)$ replacing the head's $\mathrm{A}-\mathrm{F}-\mathrm{C} \#$ with a line that not only anticipates the first two melody notes (E-D), but moves beautifully to a $\mathrm{C}$ that harmonizes the entry of that melody. The lack of third and seventh/sixth in this A chord (m. 7) means that it is less clearly an A minor chord (instead of A7) in the introduction than in the head, and the lack of a clear $\mathrm{B}-\mathrm{A}$ motion in the top voice means that the introduction lacks the closure in A minor that Martin has shown in the head. For these reasons, and because of its clear 8-bar hypermeter, the introduction strongly favors D minor.

The top staff of Example 3b shows Evans' melody in half notes as well as the remaining pitches (most of them "tensions" that may be called ninths, elevenths, and thirteenths). In mm. 1-4, each tension (shown as a small, stem-less notehead) is "absorbed" (a note or two later) into the melody line (see the lines between stem-less noteheads and melody). In mm. 5-8, the melody seems best understood in terms of the two voices given and their delayed resolutions. These delayed resolutions create another Möbius-strip-like circle.

Let us look a little more closely at $\mathrm{mm}$. 1-4 in terms of another circle-the "circle of thirds." In mm. 1-4, Evans' melody descends in thirds, accumulating the tones of an extended chord that is the goal of first four measures. To understand how this works in this passage, we start with the assumption that, in a melody, stepwise motion displaces the "trace" of a note, but leaps leave traces in our aural memory. One could argue that the $\mathrm{E}$ and $\mathrm{G}$ of $\mathrm{m} .1$ are not displaced until the $\mathrm{F}$ at the end of $\mathrm{m} .4$, but my analysis shows an implicit displacement to $\mathrm{F}$ on the downbeat of m. 2 (reasoning that the lower-register $\mathrm{F}$ and $\mathrm{E} b$ there make it difficult not to hear an implicit or octave-displaced resolution then). But either way, the notes actually sounding in m. 4 (an extended dominant) are the notes shown as collected from the "traces" of the motion through the circle of thirds that precedes it.

On the one hand, Evans' introduction provides additional circular elements with its circle of thirds and its Möbius-strip-like voice leading. On the other hand, its emphasis on $\mathrm{D}$ minor reduces somewhat the ambiguity between $\mathrm{D}$ minor and $\mathrm{A}$ minor that Martin has described. At the same time (paradoxically), the 2-, 4-, and 8-bar hypermetrical structure of the introduction provides a template against which the unusual 10-bar structure of the tune described by Martin is more effectively experienced. Thus the introduction's metric clarity 
enhances our experience of the head's metric —and thus its tonal and formalambiguity.

The form of the performance (given in Example 4) both enhances and balances its circularity. Evans takes every other section. This return to piano creates another large-scale circular aspect. Notice also the harmonic rhythm. It is common in jazz performances to use "double time"-in which the harmonic rhythm stays the same and some rhythmic pacing goes twice as fast or moves to a twice-as-fast level of subdivision. In the Kind of Blue recording, an opposite (and, to my knowledge, uncommon) effect takes place: the rhythmic pacing of some aspects stays the same while the chords in some choruses last half as long and in some choruses a quarter as long. One might say that the players actually perform successive stages of Martin's hypermetric analysis. Each soloist takes two choruses. Each pair of choruses has the basic chord durations shown in the form diagram. Thus, each pair of choruses provides one opportunity to join choruses smoothly and one opportunity to mark their boundaries with a new instrumentation and new harmonic rhythm.

Example 4. "Blue in Green" form as performed on Kind of Blue.

\begin{tabular}{|l|l|l|l|}
\hline Function & Lead & Length & $\begin{array}{l}\text { Basic Chord } \\
\text { Duration }\end{array}$ \\
\hline Intro & Evans & 4 bars & Half \\
\hline Head & Davis & 2 choruses & Whole \\
\hline \multirow{5}{*}{ Solos } & Evans & 2 choruses & Half \\
\cline { 2 - 4 } & Coltrane & 2 choruses & Half \\
\cline { 2 - 4 } & Evans & 2 choruses & Quarter \\
\cline { 2 - 4 } & Davis & 2 choruses & Whole \\
\hline Head & Evans & 2 choruses & Quarter \\
\hline
\end{tabular}

\section{KEITH WATERS}

We now turn to "Nefertiti," which first appeared on Nefertiti, recorded by the Miles Davis Quintet on June 7, 1967. ${ }^{6}$ My discussion will suggest that its melodic structure creates circularity. Its three related phrases use sequence, motivic development, and phrase length to create overlapping.

Example 5 contains a lead sheet to "Nefertiti," a 16-bar composition written by Wayne Shorter. I have annotated the lead sheet to indicate its three phrases. Phrase 1 begins in $\mathrm{m}$. 1, Phrase 2 begins at $\mathrm{m} .9$ (initiated by the pitch $\mathrm{G} \# / \mathrm{Ab}$ in the melody,) and Phrase 3 begins in $\mathrm{m} .11$ with the pitch $\mathrm{B} b$ in the melody.

${ }^{6}$ Nefertiti, Columbia CS9594, 1967; Miles Davis, trumpet; Wayne Shorter, tenor saxophone; Herbie Hancock, piano; Ron Carter, bass; Tony Williams, drums. 
Example 5 further shows that the return to the top of the form at Phrase 1 begins with the pitch $\mathrm{C}$. As a result of the opening pitches of each phrase, Phrase 1 thus continues the ascending stepwise sequence begun with Phrase 2. Example 6 shows this transpositional scheme with a slur, linking the $\mathrm{A} b$ that initiates Phrase 2, the $\mathrm{B} b$ of Phrase 3, and the $\mathrm{C}$ that then initiates Phrase 1 . This link to the $\mathrm{C}$ of Phrase 1 thus camouflages the top of the form, creating circularity.

Example 5. Wayne Shorter, "Nefertiti."
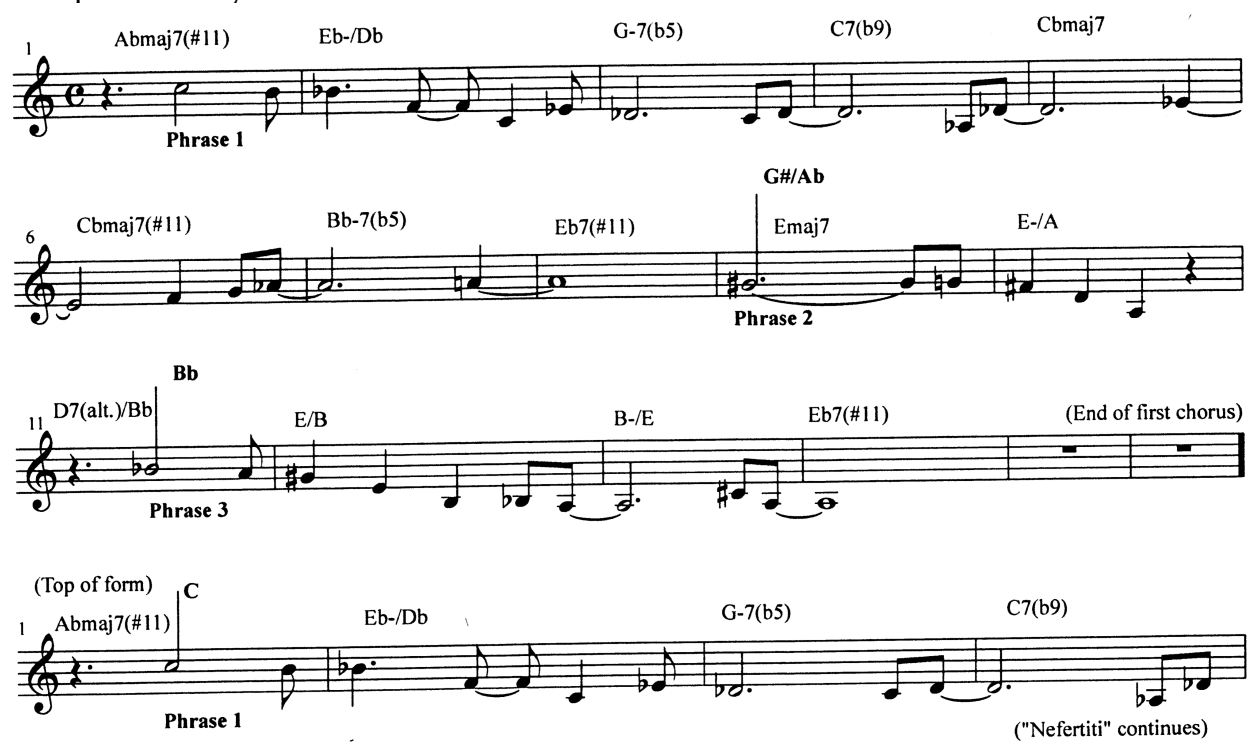

Example 6. Transpositional scheme phrases 2, 3, and 1.

$\mathrm{A} b-\mathrm{A}-\mathrm{G} \# / \mathrm{A} b$ link between phrases 1 and 2 .

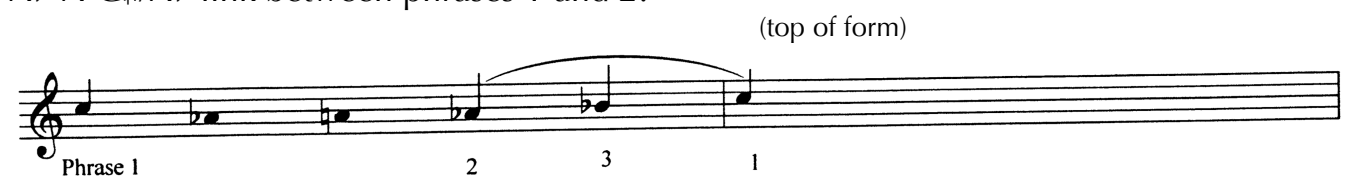

As seen in the lead sheet of Example 5, the circularity of "Nefertiti" is supported by the development and duration of these phrases. Phrase 2 is the shortest and simplest, consisting merely of two measures. Phrase 3 develops the phrase further. Phrase 1, at eight bars, is the longest and most developed of the phrases, and as a result of its duration may be heard as consequent to Phrases 2 and 3.

While this analysis might suggest that listeners hear Phrase 2 as the actual beginning point of the composition, there are musical factors that stitch Phrase 1 to Phrase 2, particularly at mm. 7, 8, and 9. This is indicated in Example 6 at mm. 7-9, which uses unstemmed noteheads; note the half step resolution from 
$A$ at $m .8$ into $G \sharp / A b$ at $m$. 9. This motion forms part of a deeper retrograde relationship between $A b / G \#$ (m. 7), $A \sharp$ (m. 8), and $A b / G \#$ (m. 9). The unstemmed noteheads are intended to suggest that the $A b$ to $A$ pitches that conclude Phrase 1 link to the $\mathrm{A} b / \mathrm{G} \#$ that begins Phrase 2. These factors enhance the composition's perpetual and seamless quality.

The recording of "Nefertiti" represents something of a watershed moment for the Davis Quintet. The group took the unusual step of recording it without conventional improvisations by horns and piano. Instead, it consists only of repeated statements of the melody by the horns rather than the more conventional head-solos-head format. The overall circular quality of "Nefertiti" may have contributed to the unusual decision by the quintet to record the piece as a series of repeated statements of the melody without conventional solos.

\section{STEVEN STRUNK}

We began our talks with a citation of factors in melody, harmony, and form that can give rise to circularity. In 1909, Phillips Barry, writing in the Journal of American Folklore, in a discussion of American folk music, refers to the first of these ideas when he states that a feature of a circular tune is "the absence of the tonic close." He also states that, ". . . in singing a ballad, whereas the incomplete close would occur many times, the final cadence would occur only once." 7 Although "Blue in Green" finds its final cadence in the middle of the tune, and only projects it as such once, "Nefertiti" ends on its last note, b2, in an incomplete close on every chorus. Even so, the Aebersold edition of "Nefertiti" specifies a slightly different final ending chord, possibly corresponding to the "final cadence that occurs only once."

Another folklorist, identified as B. H. B., writing in 1959, believes it takes more than a non-final ending to make a tune circular. He claims that "the assumption that every tune ending on a note other than its 'tonal centre' is a circular tune" is indefensible. ${ }^{8} \mathrm{He}$ says such endings are a cunning strategy "to avoid the monotony of insistence on the tonic in successive phrases, when the last phrase is followed immediately by the recurring first phrase in a manystanzaed ballad. [He goes on.] But this modest bit of variety is quite different from the impression conveyed by a true circular tune, where one has the sense of being caught in a runway that offers no exit." The latter phrase expresses more forcibly the sense of circularity, and likely refers to the second melodic procedure,

${ }^{7}$ Phillips Barry, "Folk-Music in America," The Journal of American Folklore 22/83 (March 1909): 77.

${ }^{8}$ We were unable to find Strunk's citation of B. H. B. 
a directional connection from the end to the beginning. This characteristic is found clearly on the surface of "Blue in Green," but only in the middleground of "Nefertiti," which uses the first procedure in the foreground. Consider Example 7, which shows how transpositional levels of phrase beginnings connect the second half of "Nefertiti" to the first half.

Example 7. "Nefertiti" motives and transpositions.

\begin{tabular}{|c|c|c|c|}
\hline mm. 1-2 (T0) & mm. 9-10 (T8) & mm. $11-12$ (T10) & mm. 1-2 (T0) \\
\hline $\int_{0}^{0}$ & H" & $\frac{1}{6 \theta}$ & $\frac{158}{625}$ \\
\hline goo & $=0$ & $\frac{60}{60}$ & \\
\hline
\end{tabular}

Form can also contribute a sense of circularity to a tune. Jazz players and listeners are most used to AABA forms, in which the move from $\mathrm{B}$ to the last $\mathrm{A}$ is not heard as a return to the beginning of the tune. Therefore, in the unusual $\mathrm{AAB}$ or $\mathrm{AB}$ form, the return to the opening $\mathrm{A}$ is not expected to be a return to the beginning, either-but it is. In this way the tune catches the listener in its circular trap. Nefertiti can be considered an AB form, with eight bars per section. Blue in Green has an odd number of bars, and this can also contribute to the undermining of expectations that enable the perception of circularity in a tune.

The harmonic equivalent of melodic unrest is the half cadence. Numerous Bach chorales may be heard as ending with half cadences; e. g., No. 10, Aus tiefer Not schrei' ich zu dir, an AAB bar form which starts and ends its repeated A section on $\mathrm{V}$ and ends its $\mathrm{B}$ section on $\mathrm{V}$, all in $\mathrm{A}$ minor. The first half of "Nefertiti" moves I to $\mathrm{V}$ and its second half $b \mathrm{VI}$ to $\mathrm{V}$, all in $\mathrm{A} b$. It is one of many jazz tunes composed in the 1960s and 70s by Wayne Shorter and many others that have non-tonic endings. The degree to which the last chord of a tune participates in a directional connection to the beginning varies from tune to tune. For example, the final chord of Shorter's "Yes and No," which is a ii7, is part of a long descending-fifths harmonic sequence that overlaps the end and the beginning of the tune. The final chord of "Nefertiti," by contrast, has more of the character of a true half cadence, as illustrated in Example 8. See the Roman numerals below the staff.

The first chord, which I call I, is not exactly that, although all the published versions call it Abmaj7. In the copyright deposit, Shorter did not use a chord symbol for this or for the chords in measures 2,10, or 12; he simply wrote out the notes, as shown in Example 7. The chord symbols in Example 8 come from the published sources. The first graph gives a general picture of the tune with 
practical spellings. The second graph has more analytically oriented spellings. I show a $3-$ line in $\mathrm{mm}$. 1-5: a diatonic $\hat{3}-\hat{2}-\hat{1}$ in $\mathrm{A} b$ with $\hat{2}-\hat{1}$ moving in parallel sixths with the bass $\mathrm{D} b-\mathrm{C} b$. Scale degree $\hat{1}$ at the end of this motion belongs with the $\mathrm{C} b$ bass that arrives slightly earlier, making a chromatic voice exchange prolonging I before the ii-V, at which point the $A b$ moves to the inner voice $G$, while the true upper line moves to $b 2$, creating an interruption. The second half


the voice exchange. It comes to rest, so to speak, on another interruption on b $\hat{2}$. Apparently the only way to end this tune is simply to stop on the $b 2$, and my part of this presentation will have to do likewise.

Example 8. "Nefertiti."
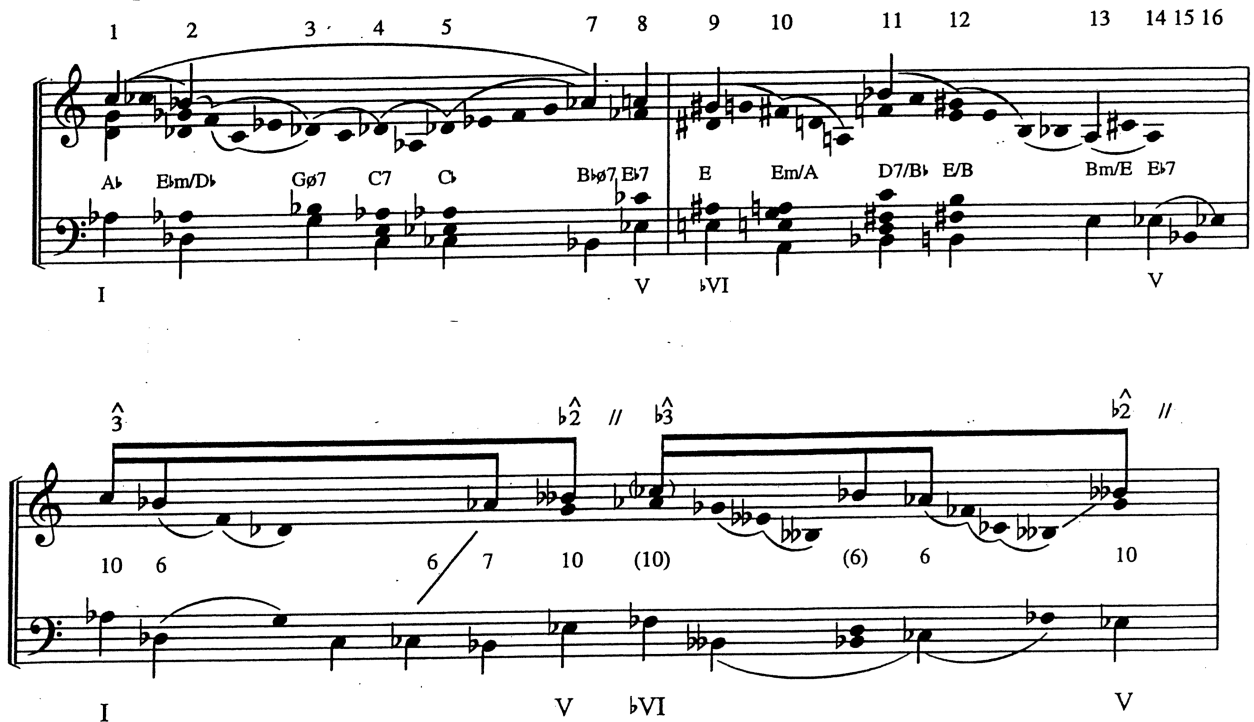

We began with a quote from Herbie Hancock in which he described one of his compositions by saying "it doesn't have any cadences, it just keeps moving around in a circle." In our presentation today, we have shown that circularity can be achieved not only through harmony, but also through other musical dimensions. These include Möbius-strip-like voice leading, the "circle of thirds," melody, form, and hypermeter. We have seen these factors contributing to the feeling of circularity in both "Blue in Green" and "Nefertiti." The late 1950s and early 1960s were a period in jazz history when musicians began to experiment with ways to circumvent the regularity of the 12-bar and 32-bar forms that were so much a part of jazz up until that time. Circular tunes that avoided feelings of conclusiveness proved to be an effective way of doing so. 


\section{BIBLIOGRAPHY AND DISCOGRAPHY}

Baker, David, Lida Belt, and Herman Hudson, eds. 1978. The Black Composer Speaks. Bloomington, Indiana: Afro-American Arts Institute. [The composition that Hancock describes (p.122) as "moving around in a circle" is "Maiden Voyage" (by Hancock). We feel that "Maiden Voyage" is at best weakly circular: it is formally regular (a 32-bar AABA tune); its lack of cadences makes it comparable to "So What" (by Miles Davis), which is also a 32-bar AABA tune without cadences.]

Barry, Phillips. 1909. "Folk-Music in America." The Journal of American Folklore 22/83 (March): 72-81.

Burton, Gary. 1966. The Time Machine. RCA Records 3642. [This album contains Steve Swallow's "Falling Grace," which is circular.]

Davis, Miles. 1959. Kind of Blue. Columbia CS1355. [This album contains Bill Evan's "Blue in Green," which is circular.]

1967. Nefertiti. Columbia CS9594. [This album contains Wayne Shorter's "Nefertiti," which is circular.]

Magee, Jeffrey. 2007. "Kinds of Blue: Miles Davis, Afro-Modernism, and the Blues," Jazz Perspectives 1/1, 5-27. [Magee's discussion of "Solar" by Miles Davis (19), suggests that he considers it to be circular since the final bar of the composition ends with a turnaround to the $\mathrm{C}$-minor opening harmony. Although performers commonly use turnarounds to set up repeated choruses, "Solar" differs in that there is no tonic cadence or return before the end of the form and, moreover, the turnaround is part of the piece's composition. This creates a true circularity, stronger than the typical end-of-form turnarounds routinely added to pieces that are not circular. Further supporting its circularity, the leading tone (B) at the end of "Solar" creates a link to the first melodic pitch (C) in m. 1.] 
Martin, Henry. 2014. "Expanding Jazz Tonality: the Compositions of Wayne Shorter." Talk delivered September 19 at the Eighth European Music Analysis Conference, University of Leuven, Belgium. [In his discussion of Shorter's "El Toro," "Iris," "Pinocchio," and "Face of the Deep," Martin argues that "Iris" is circular with a tonic of $\mathrm{C}$ minor confirmed in $\mathrm{mm}$. 9-12; he views "Pinocchio" as non-circular and weakly projecting B major, a view that can be contrasted with the one provided in Waters 2011 (230).]

Sharp, Cecil. 1907. English Folk-Song, Some Conclusions. London: Simpkin \& Co., Ltd., Novello \& Co., Ltd. [Sharp designates certain tunes as "circular," which he says "are intended to be played over and over again." (61)]

Salley, Keith. 2012. "Ordered Step Motives in Jazz Standards." Journal of Jazz Studies 8/2: 114-136. [Salley's analysis of "Nefertiti" engages issues in circular form.]

Waters, Keith. 2011. The Studio Recordings of the Miles Davis Quintet, 196568. New York: Oxford University Press. [Waters discusses the following tunes and suggests that they be considered circular: "Circle" by Miles Davis, (157-58), "Mood" by Ron Carter and Miles Davis (84), "Nefertiti" by Wayne Shorter (217-19), "Pinocchio" by Wayne Shorter (230), and "Vonetta" by Wayne Shorter (176-77).]

\section{ABOUT THE CONTRIBUTORS}

Steve Larson (1955-20iI) was the Robert M. Trotter Professor of Music at the University of Oregon. He was a pianist and the author of many papers and conference presentations on music theory. His books include Musical Forces: Motion, Metaphor, and Meaning in Music (Indiana University Press, 2012) and Analyzing Jazz: A Schenkerian Approach (Pendragon Press, 2009). His areas of specialty were Schenkerian theory, performance and analysis, jazz, the pedagogy of musicianship, and music cognition.

Henry Martin is Professor of Music at Rutgers University-Newark and a composer and music theorist. His most recent CD is Selected Piano Music, as issued by Albany Records and performed by Hilary Demske. He is founder and former chair of the Interest Group in Jazz Theory of the Society for Music Theory, and has published numerous articles on jazz theory. His book Charlie Parker and Thematic Improvisation was published by Scarecrow Press in 1996. Current 
projects include a book on Charlie Parker as composer and the composition of a complete cycle of preludes and fugues for organ.

Steven Strunk was Professor of Music at the Benjamin T. Rome School of Music at the Catholic University of America until his death in 2012. He contributed seminal articles on jazz theory to the Journal of Jazz Studies, the "Harmony" entry in the New Grove Dictionary of Jazz, and articles on the music of Wayne Shorter and Chick Corea to the Journal of Music Theory. Strunk was also a practicing composer as well as a jazz pianist who performed extensively in the Washington D.C. area.

Keith Waters is Professor of Music Theory at the University of ColoradoBoulder. He is the author of The Studio Recordings of the Miles Davis Quintet: 1965-68 (Oxford University Press), co-author with Henry Martin of Jazz: The First Hundred Years (Schirmer/Cengage), and has contributed entries to the Grove Dictionary of American Music and the Routledge Encyclopedia of Modernism. He has written numerous articles pertaining to jazz of the 1960s. As a jazz pianist, Waters has recorded and performed throughout the U.S., Europe, and in Russia and South America. 